\title{
Safer sex negotiation and parity among women in sub-Saharan Africa
}

\author{
Collins Adu $^{1 \star(\mathbb{D})}$, James Boadu Frimpong ${ }^{2}$ (D) Aliu Mohammed ${ }^{2}$ (D) Justice Kanor Tetteh ${ }^{3}$ (D), \\ Eugene Budu ${ }^{3}$, Bright Opoku Ahinkorah ${ }^{4}$ and Abdul-Aziz Seidu ${ }^{5,6,7}$ (D)
}

\begin{abstract}
${ }^{1}$ Department of Health Promotion, Education and Disability Studies, Kwame Nkrumah University of Science and Technology, Kumasi, Ghana, ${ }^{2}$ Department of Health, Physical Education and Recreation, University of Cape Coast, Cape Coast, Ghana, ${ }^{3}$ Department of Population and Health, University of Cape Coast, Cape Coast, Ghana, ${ }^{4}$ School of Public Health, Faculty of Health, University of Technology Sydney, Australia, ${ }^{5}$ College of Public Health, Medical and Veterinary Sciences, James Cook University, Townsville, Queensland, Australia, ${ }^{6}$ Department of Estate Management, Takoradi Technical University, Takoradi, Ghana and ${ }^{7}$ Centre for Gender and Advocacy, Takoradi Technical University, Takoradi, Ghana
\end{abstract}

*Corresponding author. Email: collinsadu80@yahoo.com

(Received 21 June 2021; revised 13 September 2021; accepted 16 September 2021; first published online 06 January 2022)

\begin{abstract}
Women's ability to negotiate for safer sex has effects on their sexual and reproductive health. This study investigated the association between safer sex negotiation and parity among women in sub-Saharan Africa. The data were sourced from the Demographic and Health Surveys of 28 sub-Saharan African countries conducted from 2010 to 2019. A total of 215,397 women aged 15-49 were included in the study. Multilevel logistic analysis was conducted to examine the association between safer sex negotiation and parity among women in sub-Saharan Africa. The results were presented as adjusted odds ratios (aOR) and the significance level set at $p<0.05$. The overall prevalences of safer sex negotiation and high parity among women in sub-Saharan Africa were $82.7 \%$ and $52.1 \%$, respectively. The prevalence of high parity ranged from $32.3 \%$ in Chad to $72.1 \%$ in Lesotho. The lowest prevalence of safer sex negotiation was in Chad (16.8\%) while the highest prevalence was recorded in Rwanda (99.7\%). Women who had the capacity to negotiate for safer sex were less likely to have high parity compared with those who had no capacity to negotiate for safer sex $(\mathrm{aOR}=0.78, \mathrm{CI}: 0.75-0.81)$. Other factors that were associated with high parity were age, educational level, marital status, exposure to media, contraceptive use, religion, wealth quintile, sex of household head, and place of residence. The study identified significant association between safer sex negotiation and high parity among women of reproductive age in sub-Saharan Africa. It is worth noting that women's ability to negotiate for safer sex could reduce high parity among women in sub-Saharan Africa. Therefore, policies and programmes aimed at birth control or reducing high parity among women could be targeted at improving their capacity to negotiate for safer sex through education.
\end{abstract}

Keyword: DHS; Parity; Safer sex negotiation; Sub-Saharan Africa

\section{Introduction}

Improving sexual autonomy among women comes with various benefits, including better sexual and reproductive health outcomes such as the prevention of sexually transmitted and blood-borne infections and family planning (Fadumo, 2014; Seidu et al., 2021). Women, in particular, have been disproportionately affected by sexually transmitted and blood-borne infections, especially HIV/AIDS (UNAIDS, 2013), and this is as a result of low sexual autonomy resulting from gender inequalities (Seidu et al., 2021). Sexual autonomy among women is the control women have over their own lives and the extent to which they have an equal voice with their partners in matters 
affecting themselves (Seidu et al., 2021). The Sustainable Development Goal (SDG) 5 focuses on women's empowerment to advance their rights in reproductive health decision-making, attitudes and overall ability to negotiate for safer sex with their male partners (United Nations, 2015). Policymakers, especially those in low- and middle-income countries (LMICs), are therefore beginning to pay particular attention to issues relating to women's sexual autonomy, including their ability to ask their partner(s) to use condoms during sex (Chol et al., 2019).

In sub-Saharan Africa (SSA) in particular, the normative societal organization is based on a patriarchal system where men exercise power over women. Various religious and cultural traditions and beliefs restrict sexual autonomy among women and place them in subordination to men (Chol et al., 2019). Contraceptive use remains low in SSA while it has risen to relatively high levels in many areas of Asia, Latin America and the Caribbean (Van Lith et al., 2013).

Over the past few decades, birth spacing has been a commonly used concept in family planning programmes in SSA, and is often tied to a health rationale for contraception (Westoff \& Koffman, 2010). However, there has been less focus on the group of women in SSA who want to limit childbearing (Westoff \& Koffman, 2010). Data show that the proportion of women in SSA who want to limit rather than postpone childbearing is rising steadily (Westoff, 2012). Increasing the use of contraception among these women will reduce high-risk fertility behaviours such as high-parity births, thereby contributing to the reduction of maternal mortality in the region (Stover \& Ross, 2009).

In SSA, women's ability to negotiate for safer sex has been associated with sexual and reproductive health outcomes since men are regarded as more powerful, and sometimes autocratic, when it comes to sexual decision-making (Saul et al., 2018; Darteh, 2020). In addition, associations have been found between some socio-demographic, economic and cultural factors, such a place of residence, marital status, age and educational level, and women's ability to negotiate for safer sex (Exavery et al., 2012; Darteh et al., 2014; Ameyaw et al., 2017).

Meeting women's reproductive intentions in the context of informed choice enables them to have the number of children they desire, improves the health and well-being of both women and their families, and ultimately affects macro-level health and development indicators (Atake \& Ali, 2019). To the best of the authors' knowledge, there is limited evidence regarding the prevalence of safer sex negotiation and the association between safer sex negotiation and parity among women in SSA. Therefore, this study examined this in SSA using data from the Demographic and Health Surveys (DHSs). The findings of the study could help inform policy formulation in the subSaharan African countries to reduce high parity and its negative consequences, such as maternal mortality.

\section{Methods}

\section{Data source and study design}

The study involved a cross-sectional analysis of DHS data from 28 sub-Saharan African countries. The DHS is a nationally representative study conducted globally in over 85 LMICs (Corsi et al., 2012). The survey uses a structured questionnaire to collect data on varied issues, including men's health, maternal and child health, reproductive health, nutrition and substance use (Corsi et al., 2012). The survey utilized a two-stage cluster sampling technique. Details of the sampling process have been described in a previous study (Aliaga \& Ruilin, 2006). Data for the present study were extracted from the women's file (individual recode) of the 28 DHSs. A total of 215,397 women aged 15-49 with complete cases on variables of interest were included in the study. The dataset is freely available for download at https://dhsprogram.com/data/available-datasets.cfm. The Strengthening the Reporting of Observational Studies in Epidemiology (STROBE) guidelines were followed when writing the manuscript (Von Elm et al., 2007). 


\section{Study variables}

Outcome variable

The outcome variable was parity. In the DHS, parity is defined as the number of live births of a woman. The responses were on a continuous scale of 1, 2, 3, 4, 5, 6, 7 or more and varied from one survey to another. The responses were then first coded as 'one', 'two', 'three' and 'four or more'. All women who reported having four or more births were considered to have 'high parity' (coded 1), while those reporting having one, two or three births were considered to have 'low parity' (coded 0 ). This has been adopted in several previous studies as a measure of high parity (Rahman et al., 2019; Amir-ud-Din et al., 2021).

\section{Independent variable}

The independent variable was safer sex negotiation, created as an index variable from the two variables 'can refuse sex' and 'can ask for condom use during sex'. For the first variable (can refuse sex), the respondents were asked 'whether they can refuse sex with their partner' and the question for the second variable (can ask for condom use) was 'whether they can ask their partner to use a condom during sex'. The two variables had the same response options $(1=$ no; $2=y e s ;$ and $3=$ don't know/not sure/depends). In the present study, women whose response option was $3=$ don't know/ not sure/depends were excluded from the analysis. The variable 'safer sex negotiation' was created using the remaining two responses. Women who responded 'yes' for at least one of the two variables were said to have safer sex negotiations, and those that responded 'no' for both variables were categorized as not having safer sex negotiation. This categorization was informed by previous studies that used the DHS dataset (Darteh et al., 2019; Tenkorang, 2012; Sano et al., 2018a; Putra et al., 2020; Budu et al., 2021; Seidu et al., 2021).

\section{Control variables}

Eleven control variables were included in the analysis: individual-level factors (maternal age, maternal educational level, mass media exposure, contraceptive use, decision-making capacity, employment status, religion, and marital status) and household-level factors (wealth quintile, sex of household head, and place of residence). These control variables were selected based on their availability in the dataset and parsimony with safer sex negotiation from literature (Tenkorang, 2012; Atteraya et al., 2014; Ung et al., 2014; Sano et al., 2018a; Feyisetan \& Oyediran, 2019; Putra et al., 2020). Existing coding for maternal age, wealth quintile, sex of household head and place of residence found in the standard DHS was used. Women's educational level was coded as no education, primary, secondary or higher. Marital status was re-coded as married or cohabiting. Religious affiliation was coded as Christianity, Islam and other. The coding of the rest of the control variables can be found in Table 2 .

\section{Statistical analyses}

Data extraction, re-coding and final analyses were carried out using Stata version 16.0. Three levels of analyses were conducted. First, percentages were used to present the prevalences of high parity and safer sex negotiation (Figures 1 and 2, respectively). Secondly, Pearson's chi-squared test was conducted to determine the distribution and relationship between high parity and safer sex negotiation (Table 2). Finally, multilevel logistic regression models were built to determine the association between safer sex negotiation and high parity among women in SSA. Model 0 showed the variance in high parity attributed to the clustering of the primary sampling units (PSUs) without the explanatory variables. Models I and II contained the individual- and household-level factors, respectively. The final model (Model III) had all the individual- and household-level factors. The Stata command melogit was used when fitting these models. Akaike's Information Criterion (AIC) 
Figure 1. Prevalence of high parity among women in sub-Saharan Africa.

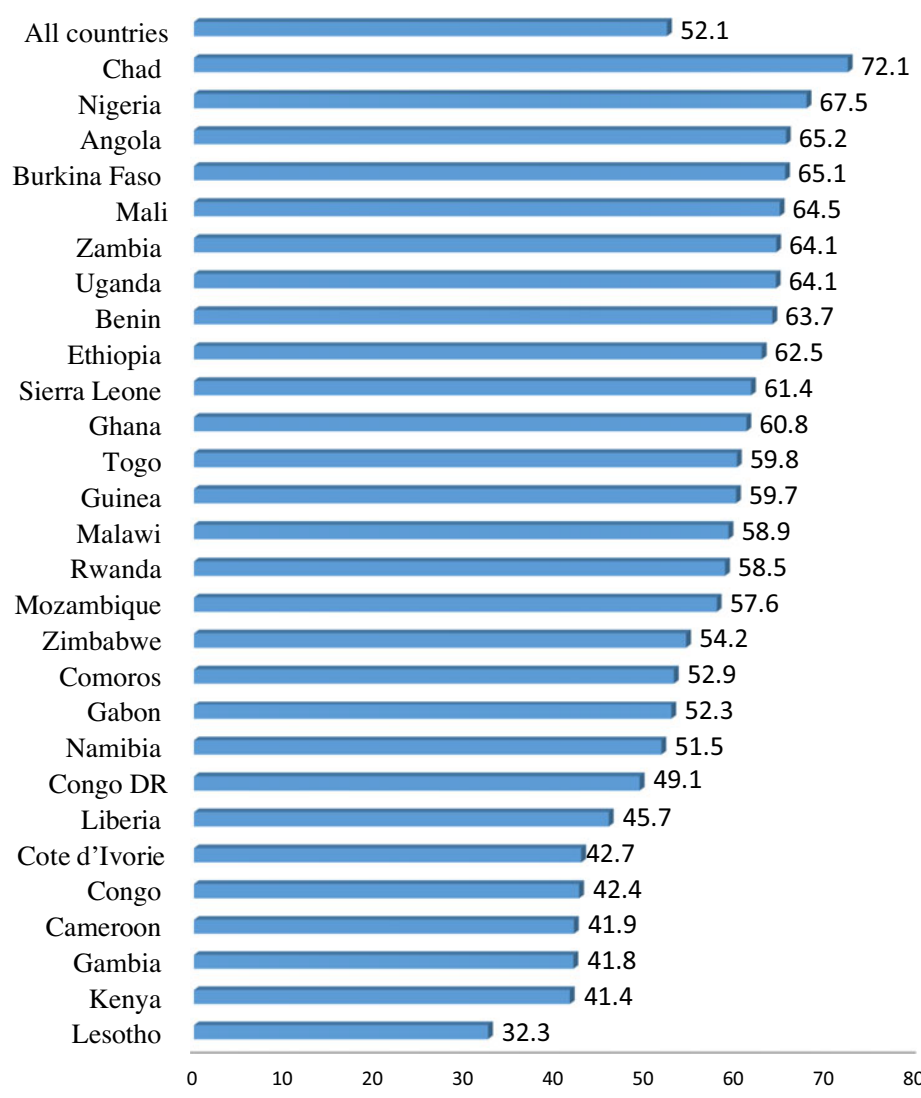

tests for model comparison were used (Table 3). The results of the regression analyses are presented in tabular form using adjusted odds ratios (aORs) with respective confidence intervals (CIs). Statistical significance was set at $p<0.05$ in the chi-squared and regression analyses. The women's sample weights (v005/1,000,000) were applied to obtain unbiased estimates according to DHS guidelines and the survey command svy in Stata was used to adjust for the complex sampling structure of the data in the chi-squared and regression analyses.

\section{Results}

\section{Prevalence of high parity and safer sex negotiation among women in sub-Saharan Africa}

The overall prevalence of high parity in SSA was $52.1 \%$, with in-country variations (Figure 1). Chad recorded the highest prevalence $(72.1 \%)$ with Lesotho recording the lowest $(32.3 \%)$. With regards to safer sex negotiation, a high prevalence of $82.7 \%$ was recorded in SSA, with the highest country-level prevalence found in Rwanda (99.7\%) and the lowest observed in Chad (16.8\%) Figure 2.

High parity was more prevalent among women aged 25 and above, those with no formal education $(73.7 \%)$ or primary education $(64.2 \%)$, those who were married $(64.4 \%)$, those in the poorest wealth quintile (68.4\%) and women who were residing in rural areas (66.3\%) compared with women who were younger than 25 years, those with at least secondary education, those who were cohabiting, those in the richest wealth quintile and women residing in urban areas (Table 2). 


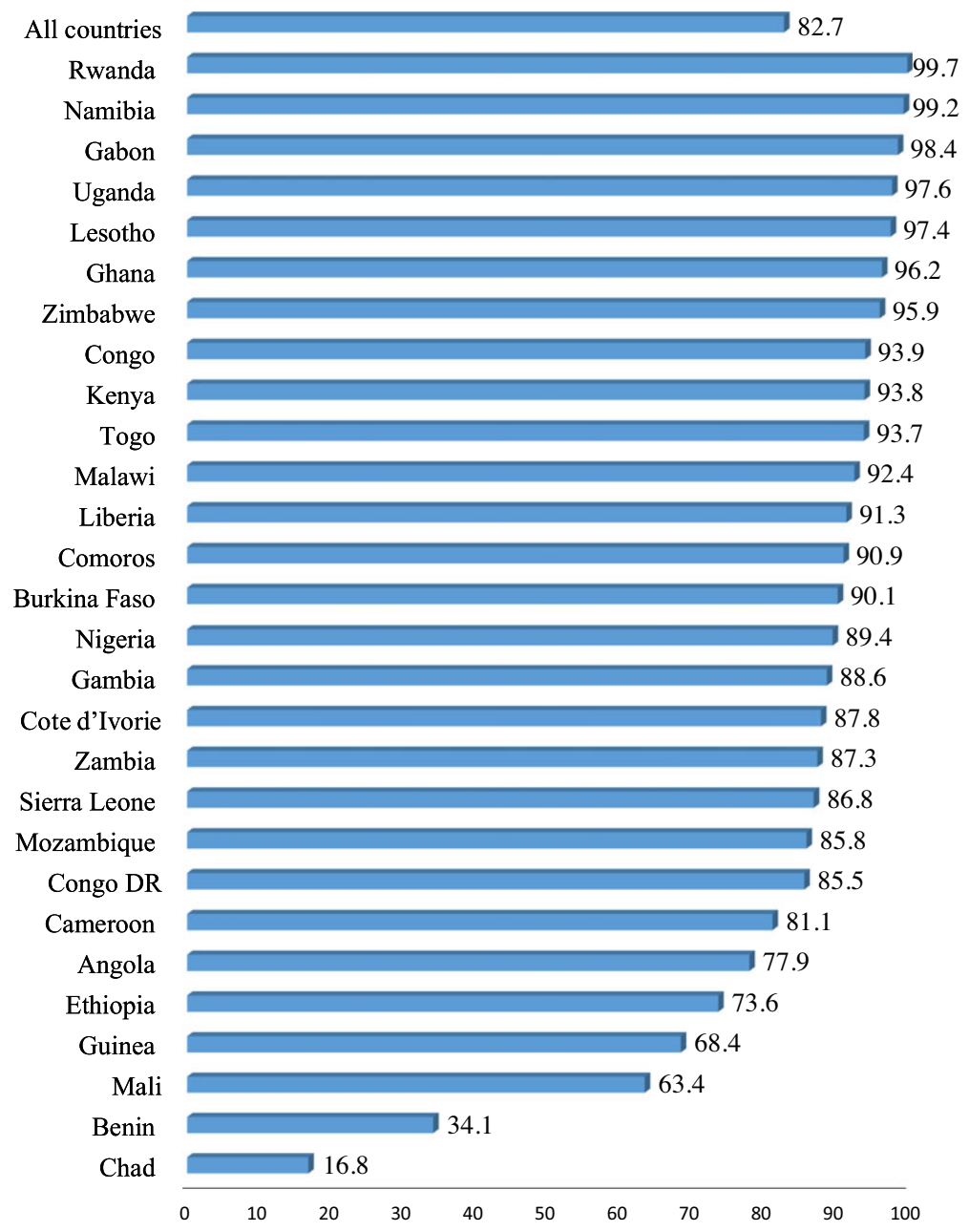

Figure 2. Prevalence of safer sex negotiation among women in sub-Saharan Africa.

\section{Association between safer sex negotiation and high parity among women in sub-Saharan Africa}

Table 3 shows the association between safer sex negotiation and high parity among women in SSA. Women who had the capacity to negotiate for safer sex were less likely to have high parity compared with those who had no capacity to negotiate for safer sex ( $\mathrm{aOR}=0.78, \mathrm{CI}$ : 0.75-0.81).

\section{Discussion}

This study sought to investigate the association between safer sex negotiation and high parity among women of reproductive age in SSA using data from the DHS of 28 countries. The prevalence of high parity among women in SSA was $52.1 \%$, with Chad having the highest prevalence of $72.1 \%$ and Lesotho the lowest $(32.3 \%)$. With regard to safer sex negotiation, the findings indicate a prevalence of $82.7 \%$ among women in SSA, with women in Rwanda (99.7\%) and Chad (16.8\%) having the highest and lowest prevalence rates, respectively. The findings also suggest an inverse 
Table 1. Description of study sample of women aged $15-49$, sub-Saharan Africa

\begin{tabular}{|c|c|c|c|}
\hline Country & Survey year & Weighted $n$ & Weighted \% \\
\hline Angola & 2015-16 & 6803 & 3.2 \\
\hline Burkina Faso & 2010 & 13,081 & 6.1 \\
\hline Benin & 2018-19 & 10,715 & 5.0 \\
\hline Congo DR & 2013-14 & 10,615 & 4.9 \\
\hline Congo & 2011-12 & 5947 & 2.8 \\
\hline Cote d'Ivoire & 2011-12 & 5580 & 2.6 \\
\hline Cameroon & 2018 & 7146 & 3.3 \\
\hline Ethiopia & 2016 & 8902 & 4.1 \\
\hline Gabon & 2012 & 4143 & 1.9 \\
\hline Ghana & 2014 & 5049 & 2.3 \\
\hline Gambia & 2013 & 6484 & 3.0 \\
\hline Guinea & 2018 & 5933 & 2.7 \\
\hline Kenya & 2014 & 8219 & 3.8 \\
\hline Comoros & 2012 & 2514 & 1.2 \\
\hline Liberia & 2013 & 5114 & 2.4 \\
\hline Lesotho & 2014 & 1729 & 0.8 \\
\hline Mali & 2018 & 7856 & 3.6 \\
\hline Malawi & 2015-16 & 15,731 & 7.3 \\
\hline Mozambique & 2015 & 3,468 & 1.6 \\
\hline Nigeria & 2018 & 20,386 & 9.5 \\
\hline Namibia & 2013 & 2967 & 1.4 \\
\hline Rwanda & 2014-15 & 6814 & 3.2 \\
\hline Sierra Leone & 2019 & 9109 & 4.2 \\
\hline Chad & 2014-15 & 11,034 & 5.1 \\
\hline Togo & 2013-14 & 5740 & 2.7 \\
\hline Uganda & 2016 & 10,815 & 5.0 \\
\hline Zambia & 2015 & 7510 & 3.5 \\
\hline Zimbabwe & 2015 & 5991 & 2.8 \\
\hline Total & & 215,397 & 100 \\
\hline
\end{tabular}

relationship between women's ability to negotiate for safer sex and high parity in SSA. Specifically, women who had increased ability to negotiate for safer sex had decreased odds for high parity, while those who had decreased ability to negotiate for safer sex had increased odds for high parity. Other factors that were associated with high parity were age, educational level, marital status, exposure to media, contraceptive use, religion, wealth quintile, sex of household head and place of residence.

The prevalence of high parity in SSA recorded in this study (52.1\%) supports the findings of previous studies, which suggested that the majority of women in SSA have high parity, albeit with country-level differences (Van Lith et al., 2013; Atake \& Ali, 2019; Vollset et al., 2020). In spite of 
Table 2. Distribution of high parity among women aged $15-49$ by safer sex negotiation and other covariates in sub-Saharan Africa

\begin{tabular}{|c|c|c|c|c|}
\hline Variable & Weighted $n$ & Weighted \% & High parity & $\chi^{2}$ \\
\hline Safer sex negotiation & & & & $<0.001$ \\
\hline No & 38,000 & 17.6 & 67.8 & \\
\hline Yes & 177,397 & 82.4 & 60.8 & \\
\hline Age (years) & & & & $<0.001$ \\
\hline $15-19$ & 13,854 & 6.4 & 1.4 & \\
\hline $20-24$ & 36,992 & 17.2 & 21.1 & \\
\hline $25-29$ & 46,820 & 21.7 & 56.3 & \\
\hline $30-34$ & 40,646 & 18.9 & 77.0 & \\
\hline $35-39$ & 34,562 & 16.1 & 86.3 & \\
\hline $40-44$ & 24,075 & 11.2 & 89.2 & \\
\hline $45-49$ & 18,477 & 8.6 & 90.7 & \\
\hline Education & & & & $<0.001$ \\
\hline No education & 81,464 & 37.8 & 73.7 & \\
\hline Primary & 68,527 & 31.8 & 64.2 & \\
\hline Secondary + & 65,406 & 30.4 & 45.4 & \\
\hline Marital status & & & & $<0.001$ \\
\hline Married & 171,410 & 79.6 & 64.4 & \\
\hline Cohabiting & 43,987 & 20.4 & 53.0 & \\
\hline Mass media exposure & & & & $<0.001$ \\
\hline Not exposed & 78,530 & 36.5 & 66.7 & \\
\hline Exposed & 136,867 & 63.5 & 59.4 & \\
\hline Contraceptive use & & & & $<0.001$ \\
\hline No & 151,699 & 70.4 & 61.2 & \\
\hline Yes & 63,698 & 29.6 & 64.1 & \\
\hline Employment status & & & & $<0.001$ \\
\hline Not working & 54,772 & 25.4 & 53.9 & \\
\hline Working & 160,625 & 74.6 & 64.9 & \\
\hline \multicolumn{5}{|l|}{ Religion } \\
\hline Christianity & 132,985 & 61.7 & 60.4 & \\
\hline Islam & 72,579 & 33.7 & 64.3 & \\
\hline Other & 9834 & 4.6 & 68.2 & \\
\hline Decision-making capacity & & & & $<0.001$ \\
\hline Alone & 46,585 & 21.6 & 63.3 & \\
\hline Not alone & 168,812 & 78.4 & 617 & \\
\hline
\end{tabular}


Table 2. (Continued)

\begin{tabular}{|c|c|c|c|c|}
\hline Variable & Weighted $n$ & Weighted \% & High parity & $\chi^{2}$ \\
\hline Wealth quintile & & & & $<0.001$ \\
\hline Poorest & 40,262 & 18.7 & 68.4 & \\
\hline Poorer & 43,016 & 20.0 & 66.5 & \\
\hline Middle & 42,965 & 19.9 & 65.0 & \\
\hline Richer & 443,473 & 20.6 & 60.3 & \\
\hline Richest & 44,779 & 20.8 & 51.0 & \\
\hline Sex of household head & & & & $<0.001$ \\
\hline Male & 181,683 & 84.4 & 62.9 & \\
\hline Female & 33,714 & 15.6 & 57.8 & \\
\hline Place of residence & & & & $<0.001$ \\
\hline Urban & 78,315 & 36.4 & 54.7 & \\
\hline Rural & 137,082 & 63.6 & 66.3 & \\
\hline
\end{tabular}

significant decline in the rate of population growth in SSA, the majority of women continue to have parity three or higher, largely due to low levels of educational attainment and contraceptive use and other socio-cultural factors (Yaya et al., 2018; Vollset et al., 2020). The prevalence of high parity was highest in Chad (72.1\%) and lowest in Lesotho (32.3\%). The high literacy rate and low contraceptive use in Chad relative to Lesotho (Yaya et al., 2018) might have accounted for the greater prevalence of high parity in Chad. For example, recent estimates by UNESCO (2021) have revealed that $56.5 \%$ of the female population in Chad are illiterate as against $22.6 \%$ in Lesotho.

With regard to safer sex negotiation, $82.7 \%$ of the women surveyed had the capacity to negotiate for safer sex. Similar studies in SSA have reported a high prevalence of safer sex negotiation among women in SSA (Aboagye et al., 2021; Seidu et al., 2021). The increasing prevalence of safer sex negotiation among women in SSA could be due to factors such as improved access to education and mass media exposure (Aboagye et al., 2021; Seidu et al., 2021). Previous studies have reported that education and exposure to mass media are associated with increasing women's empowerment and decision-making capacity, which influence their ability to negotiate for safer sex (De Coninck et al., 2014; Seidu et al., 2020). As found in this study, education, mass media exposure, household wealth and sex of household are associated with women's ability to negotiate for safer sex. Perhaps, varied levels of these factors in different countries in SSA could account for the different prevalence of safer sex negotiations among women in different countries in SSA. For instance, while $99.7 \%$ of women in Rwanda reported having the capacity to negotiate for safer sex, only $16.8 \%$ of the women in Chad did. The high literacy rate and media exposure in Rwanda relative to Chad might have contributed to the higher prevalence of safer sex negotiation in Rwanda compared with Chad (Aboagye et al., 2021).

Women's capacity to negotiate the conditions and timing of sex is important in determining parity and other maternal health outcomes (Seidu et al., 2021). In this study, women who had increased ability to negotiate for safer sex had decreased odds of high parity and vice versa. This finding supports findings from previous studies in SSA (Seidu et al., 2021) and Nepal (Atteraya et al., 2014). A plausible reason for this is the increased tendency for women with the ability to negotiate for safer sex, to refuse sex or to ask their partners to use condoms or other family planning methods during sex with the aim of avoiding unintended pregnancies or limit parity (Atteraya et al., 2014). Also, women's ability to negotiate for safer sex is a function of their autonomy regarding their participation in decision-making, including family size and birth 
Table 3. Factors associated with high parity among women aged 15-49 in sub-Saharan Africa

\begin{tabular}{|c|c|c|c|c|}
\hline Variable & Model 0 & $\begin{array}{c}\text { Model I } \\
\text { aOR }(95 \% \mathrm{Cl})\end{array}$ & $\begin{array}{c}\text { Model II } \\
\text { aOR }(95 \% \mathrm{Cl})\end{array}$ & $\begin{array}{c}\text { Model III } \\
\text { aOR }(95 \% \mathrm{CI})\end{array}$ \\
\hline \multicolumn{5}{|c|}{ Safer sex negotiation } \\
\hline \multicolumn{5}{|l|}{ No (Ref.) } \\
\hline Yes & & $0.80^{\star \star \star}(0.78-0.83)$ & & $0.78^{\star \star \star}(0.75-0.81)$ \\
\hline \multicolumn{5}{|l|}{ Age } \\
\hline \multicolumn{5}{|l|}{ 15-19 (Ref.) } \\
\hline $20-24$ & & $18.49^{\star \star \star}(16.20-21.07)$ & & $18.94^{\star \star \star}(16.61-21.60)$ \\
\hline $25-29$ & & $101.8^{\star \star \star}(89.31-116.0)$ & & $111.6^{\star \star \star}(97.91-127.1)$ \\
\hline $30-34$ & & $274.9^{\star \star \star}(241.0-313.6)$ & & $321.1^{\star \star \star}(281.4-366.4)$ \\
\hline $35-39$ & & $505.5^{\star \star \star}(442.4-577.6)$ & & $604.2^{\star \star \star}(528.6-690.7)$ \\
\hline $40-44$ & & $643.5^{\star \star \star}(561.6-737.3)$ & & $774.6^{\star \star \star}(675.7-887.9)$ \\
\hline $45-49$ & & $706.5^{\star \star \star}(615.0-811.7)$ & & $849.5^{\star \star \star}(739.1-976.4)$ \\
\hline \multicolumn{5}{|l|}{ Education } \\
\hline \multicolumn{5}{|c|}{ No education (Ref.) } \\
\hline Primary & & $0.82^{\star \star \star}(0.79-0.84)$ & & $0.89^{\star \star \star}(0.86-0.91)$ \\
\hline Secondary+ & & $0.29^{\star \star \star}(0.28-0.30)$ & & $0.41^{\star \star \star}(0.40-0.42)$ \\
\hline \multicolumn{5}{|l|}{ Marital status } \\
\hline \multicolumn{5}{|c|}{ Married (Ref.) } \\
\hline Cohabiting & & $0.99(0.96-1.02)$ & & $0.97^{\star}(0.94-1.00)$ \\
\hline \multicolumn{5}{|c|}{ Mass media exposure } \\
\hline \multicolumn{5}{|c|}{ Not exposed (Ref.) } \\
\hline Exposed & & $0.72^{\star \star \star}(0.70-0.73)$ & & $0.87^{\star \star \star}(0.84-0.89)$ \\
\hline \multicolumn{5}{|c|}{ Contraceptive use } \\
\hline \multicolumn{5}{|l|}{ No (Ref.) } \\
\hline Yes & & $1.45^{\star \star \star}(1.42-1.49)$ & & $1.52^{\star \star \star}(1.48-1.56)$ \\
\hline \multicolumn{5}{|c|}{ Employment status } \\
\hline \multicolumn{5}{|c|}{ Not working (Ref.) } \\
\hline Working & & $1.04^{\star \star}(1.01-1.07)$ & & $0.98(0.95-1.01)$ \\
\hline \multicolumn{5}{|l|}{ Religion } \\
\hline \multicolumn{5}{|c|}{ Christianity (Ref.) } \\
\hline Islam & & $1.10^{\star \star \star}(1.07-1.13)$ & & $1.18^{\star \star \star}(1.14-1.21)$ \\
\hline Other & & $1.19^{\star \star \star}(1.13-1.26)$ & & $1.13^{\star \star *}(1.07-1.20)$ \\
\hline \multicolumn{5}{|c|}{ Decision-making capacity } \\
\hline \multicolumn{5}{|l|}{ Alone (Ref.) } \\
\hline Not alone & & $1.02(0.99-1.05)$ & & $0.98(0.96-1.01)$ \\
\hline
\end{tabular}


Table 3. (Continued)

\begin{tabular}{|c|c|c|c|c|}
\hline Variable & Model 0 & $\begin{array}{c}\text { Model I } \\
\text { aOR }(95 \% \mathrm{Cl})\end{array}$ & $\begin{array}{c}\text { Model II } \\
\text { aOR }(95 \% \mathrm{Cl})\end{array}$ & $\begin{array}{c}\text { Model III } \\
\text { aOR }(95 \% \mathrm{CI})\end{array}$ \\
\hline \multicolumn{5}{|l|}{ Wealth quintile } \\
\hline \multicolumn{5}{|l|}{ Poorest (Ref.) } \\
\hline Poorer & & & $0.92^{\star \star \star}(0.89-0.94)$ & $0.93^{\star \star \star}(0.90-0.97)$ \\
\hline Middle & & & $0.88^{\star \star \star}(0.85-0.90)$ & $0.83^{\star \star \star}\left(0.80-{ }^{\star} 0.97\right)$ \\
\hline Richer & & & $0.77^{\star \star \star}(0.75-0.80)$ & $0.66^{\star * *}(0.63-0.69)$ \\
\hline Richest & & & $0.56^{\star \star \star}(0.54-0.58)$ & $0.40^{\star \star \star}(0.38-0.42)$ \\
\hline \multicolumn{5}{|l|}{ Sex of household head } \\
\hline \multicolumn{5}{|l|}{ Male (Ref.) } \\
\hline Female & & & $1.24^{\star \star \star}(0.80-0.84)$ & $0.76^{\star \star \star}(0.74-0.79)$ \\
\hline \multicolumn{5}{|l|}{ Place of residence } \\
\hline \multicolumn{5}{|l|}{ Urban (Ref.) } \\
\hline Rural & & & $1.24^{\star \star \star}(1.21-1.27)$ & $1.17^{\star \star \star}(1.14-1.21)$ \\
\hline \multicolumn{5}{|l|}{ Random effect results } \\
\hline PSU variance $(95 \% \mathrm{Cl})$ & $0.011(0.008-0.014)$ & $0.016(0.012-0.021)$ & $0.007(0.005-0.010)$ & $0.012(0.008-0.017)$ \\
\hline ICC & 0.0032372 & 0.0047206 & 0.0022215 & 0.0035469 \\
\hline LR test & $430.65\left(\chi^{2}=0.000\right)$ & $89.13\left(\chi^{2}=0.000\right)$ & $57.95\left(\chi^{2}=0.000\right)$ & $53.88\left(\chi^{2}=0.000\right)$ \\
\hline Wald $\chi^{2}$ & Ref. & $50,877.93^{\star \star \star}$ & $4043.45^{\star \star \star}$ & $51,862 \cdot 16^{\star \star \star}$ \\
\hline \multicolumn{5}{|l|}{ Model fitness } \\
\hline Log-likelihood & $-141,964.25$ & $-94,372.652$ & $-139,934.25$ & $-92,552.337$ \\
\hline AIC & $283,932.5$ & $188,781.3$ & $279,884.5$ & $185,152.7$ \\
\hline N & 215,397 & 215,397 & 215,397 & 215,397 \\
\hline Number of clusters & 1612 & 1612 & 1612 & 1612 \\
\hline
\end{tabular}

PSU Variance=primary sampling unit variance; ICC=intraclass correlation coefficient; $L R$ test=likelihood ratio test; $A I C=A k a i k e$ information criterion.

$p<0.005^{\star \star} ; p<0.01^{\star \star \star} ; p<0.001$.

spacing (Stanfors \& Larsson, 2014; Ung et al., 2014). Thus, women's empowerment is a strategic approach to increasing their ability to negotiate for safer sex and limit their number of births (Seidu et al., 2021).

The present study showed that women with primary, secondary and higher education had lower odds of high parity compared with women with no education. Education can delay marriages and childbearing as well as improve women's economic viability and hence reduce their risk of giving birth to many children (Stanfors \& Larsson, 2014). Therefore, there is a need for concerted efforts and strategies to promote girl-child education since it appears to be one of the best approaches to limiting high parity, especially in countries with lower rates of educational attainment such as Chad.

Although the use of contraceptives is widely assumed to reduce the prevalence of high parity (Van Lith et al., 2013; Yaya et al., 2018), the findings of this study suggest that women who use contraceptives have higher odds of high parity compared with those who do not use contraceptives. This finding is supported by those of previous studies in Kenya (Ettarh \& Kyobutungi, 2012) and Ethiopia (Lakew et al., 2013). Perhaps the majority of the women who use contraceptives in 
SSA might do so only after attaining high parity. Thus, contraceptives may be largely used by highparity women who want to stop childbearing but not as a means of avoiding high parity (Lakew et al., 2013). This could limit the benefits of contraceptives as a means of avoiding high parity among women in SSA. Therefore, considering the increased risk for maternal and child morbidity and mortality associated with high parity (Stover \& Ross, 2013; Brown et al., 2015; Abedin \& Arunachalam, 2020), it is important for policymakers not only to promote the use of contraceptives among women but also to ensure their appropriate use to prevent high parity.

The main strength of this study was the use of the most recent nationally representative DHS datasets of 28 sub-Saharan African countries. Apart from using well-trained enumerators in data collection, the appropriateness of the statistical tool used for the analysis, coupled with the probability method employed in selecting respondents, makes the findings of this study robust and generalizable to women of reproductive age in SSA. However, the findings only suggest an association between safer sex negotiation and parity and not causality, since the study relied on crosssectional data. Also, both the ability to negotiate for safer sex and parity were self-reported and may have been affected by social desirability bias.

In conclusion, this study identified a significant association between safer sex negotiation and high parity among women of reproductive age in SSA. The findings suggest that women's ability to negotiate for safer sex could reduce high parity among women in SSA. Therefore, policies and programmes aimed at birth control or reducing high parity among women could be targeted at improving their capacity to negotiate for safer sex. Such interventions could be targeted at empowering women and improving their decision-making capacity through education, access to mass media and employment. Such interventions could reduce high parity among women and improve maternal and child health outcomes in SSA.

Funding. The study received no funding.

Conflicts of Interest. The authors declare that they have no competing interests.

Ethical Approval. Ethical approval was not required for this study since the DHS datasets are publicly available. The DHS reports showed that ethical clearances were obtained from the Ethics Committee of ORC Macro Inc., as well as the Ethics Boards of the partner organizations of the various countries, including the Ministries of Health. The survey was conducted with adherence to the standards for ensuring the protection of respondents' privacy. ICF International ensures that the survey complies with the US Department of Health and Human Services' regulations for the respect of human subjects. Further information about the DHS data usage and ethical standards is available at http://goo.gl/ny8T6X.

\section{References}

Abedin S and Arunachalam D (2020) Maternal autonomy and high-risk pregnancy in Bangladesh: the mediating influences of childbearing practices and antenatal care. BMC Pregnancy and Childbirth 20(1), 1-8.

Aboagye RG, Ahinkorah BO, Seidu AA, Adu C, Hagan JE, Amu H and Yaya S (2021) Mass media exposure and safer sex negotiation among women in sexual unions in sub-Saharan Africa: analysis of Demographic and Health Survey data. Behavioral Sciences 11(5), 63.

Aliaga A and Ruilin R (2006) Cluster optimal sample size for Demographic and Health Surveys. In 7th International Conference on Teaching Statistics - ICOTS, Vol, 7, pp. 2-7.

Ameyaw EK, Appiah F, Agbesi CS and Kannor P (2017) Contraceptive use in Ghana: what about women empowerment? Advances in Sexual Medicine 7(1), 44-64.

Amir-ud-Din R, Naz L, Rubi A, Usman M and Ghimire U (2021) Impact of high-risk fertility behaviours on underfive mortality in Asia and Africa: evidence from Demographic and Health Surveys. BMC Pregnancy and Childbirth 21, 344, doi.org/10.1186/s12884-021-03780-y.

Atake E H and Ali P G (2019) Women's empowerment and fertility preferences in high fertility countries in Sub-Saharan Africa. BMC Women's Health 19(1), 54.

Atteraya MS, Kimm H and Song IH (2014) Women's autonomy in negotiating safer sex to prevent HIV: findings from the 2011 Nepal Demographic and Health Survey. AIDS Education and Prevention 26(1), 1-12. 
Brown W, Ahmed S, Roche N, Sonneveldt E and Darmstadt GL (2015) Impact of family planning programs in reducing high-risk births due to younger and older maternal age, short birth intervals, and high parity. Seminars in Perinatology 39(5), 338-344.

Budu E, Ahinkorah BO, Seidu AA, Hagan JE, Agbemavi W, Frimpong JB et al. (2021) Child marriage and sexual autonomy among women in Sub-Saharan Africa: evidence from 31 Demographic and Health Surveys. International Journal of Environmental Research and Public Health 18(7), 3754.

Chol C, Negin J, Agho KE and Cumming RG (2019) Women's autonomy and utilisation of maternal healthcare services in 31 Sub-Saharan African countries: results from the Demographic and Health Surveys, 2010-2016. BMJ Open 9, e023128.

Corsi D, Neuman M, Finlay JE and Subramanian SV (2012) Demographic and Health Surveys: a profile. International Journal of Epidemiology 41(6), 1602-1613.

Darteh EK (2020) Individual and contextual predictors of comprehensive HIV and AIDS knowledge among young females in Ghana. African Journal of AIDS Research 19(3), 222-230.

Darteh EKM, Dickson KS and Doku DT (2019) Women's reproductive health decision-making: a multi-country analysis of Demographic and Health Surveys in sub-Saharan Africa. PloS One 14(1), e0209985.

Darteh EKM, Doku DT and Esia-Donkoh K (2014) Reproductive health decision making among Ghanaian women. Reproductive Health 11(1), 1-8.

De Coninck Z, Feyissa IA, Ekström AM and Marrone G (2014) Improved HIV awareness and perceived empowerment to negotiate safe sex among married women in Ethiopia between 2005 and 2011. PloS One 9(12), el15453.

Ettarh RR and Kyobutungi C (2012) Physical access to health facilities and contraceptive use in Kenya: evidence from the 2008-2009 Kenya Demographic and Health Survey. African Journal of Reproductive Health 16(3) 47-55.

Exavery A, Kanté AM, Jackson E, Noronha J, Sikustahili G, Tani K et al. (2012) Role of condom negotiation on condom use among women of reproductive age in three districts in Tanzania. BMC Public Health 12(1), 1-11.

Fadumo R (2014) The association between women's autonomy and women's HIV/AIDS knowledge and attitudes in Ethiopia. Electronic Thesis and Dissertation Repository,1992. URL: https://ir.lib.uwo.ca/etd/1992.

Feyisetan B and Oyediran K A (2019) Can married or cohabiting women negotiate protective sex ? Findings from Demographic and Health Surveys of two West African countries. Journal of Biosocial Science, https://doi.org/10.1017/ S0021932019000798

Lakew Y, Reda AA, Tamene H, Benedict S and Deribe K (2013) Geographical variation and factors influencing modern contraceptive use among married women in Ethiopia: evidence from a national population based survey. Reproductive Health 10(1), 1-10.

Loiseau E and Nowacka K (2015) Can Social Media Effectively Include Women's Voices in Decision-Making Processes? Organisation for Economic Cooperation and Development, Paris.

Putra IGNE, Dendup T and Januraga PP (2020) The roles of women empowerment on attitude for safer sex negotiation among Indonesian married women. Women and Health, doi.org/10.1080/03630242.2020.1831685

Rahman M, Hosen A and Khan MA (2019) Association between maternal high-risk fertility behavior and childhood morbidity in Bangladesh: a nationally representative cross-sectional survey. American Journal of Tropical Medicine and Hygiene 101(4), 929-936.

Sano Y, Antabe R, Atuoye KN, Braimah JA, Galaa SZ and Luginaah I (2018a) Married women's autonomy and postdelivery modern contraceptive use in the Democratic Republic of Congo. BMC Women's Health 18(1), 1-7.

Sano Y, Sedziafa AP, Vercillo S, Antabe R and Luginaah I (2018b) Women's household decision-making autonomy and safer sex negotiation in Nigeria: an analysis of the Nigeria Demographic and Health Survey. AIDS Care 30(2), 240-245.

Saul J, Bachman G, Allen S, Toiv NF, Cooney C and Beamon TA (2018) The DREAMS core package of interventions: a comprehensive approach to preventing HIV among adolescent girls and young women. PloS One 13(12), e0208167.

Seidu AA, Aboagye RG, Okyere J, Agbemavi W, Akpeke M, Budu E et al. (2021) Women's autonomy in household decision-making and safer sex negotiation in sub-Saharan Africa: an analysis of data from 27 Demographic and Health Surveys. SSM-Population Health 14, 100773.

Seidu AA, Ahinkorah BO, Hagan Jr JE, Ameyaw EK, Abodey E, Odoi A et al. (2020) Mass media exposure and women's household decision-making capacity in 30 sub-Saharan African countries: analysis of Demographic and Health Surveys. Frontiers in Psychology 11, 581614.

Stanfors M and Larsson C (2014) Women's education, empowerment, and contraceptive use in sub-Saharan Africa: findings from recent Demographic and Health Surveys. Etude de la Population Africaine 28(2), 1022-1034.

Stover J and Ross J (2009) How increased contraceptive use has reduced maternal mortality. Maternal Child Health Journal 14(5), 687-695.

Stover J and Ross J (2013) Changes in the distribution of high-risk births associated with changes in contraceptive prevalence. BMC Public Health 13(3), 1-9.

Tenkorang EY (2012) Negotiating safer sex among married women in Ghana. Archives of Sexual Behavior 41(6), 1353-1362.

UNAIDS (2013) HIV/AIDS Fact Sheet. URL: https://www.unaids.org/en/resources/documents/2013/20130923_UNAIDS_ Global_Report_2013 (accessed 24th May 2021). 
UNESCO (2021) National Monitoring: Percentage of Illiterates who are Female. United Nations Educational, Scientific and Cultural Organization. URL: http://data.uis.unesco.org/ (accessed 24th May 2021).

Ung M, Boateng GO, Armah FA, Amoyaw JA, Luginaah I and Kuuire V (2014) Negotiation for safer sex among married women in Cambodia: the role of women's autonomy. Journal of Biosocial Science 46(1), 90-106.

United Nations (2015) Transforming Our World: The 2030 Agenda for Sustainable Development. United Nations, New York.

Van Lith LM, Yahner M and Bakamjian L (2013) Women's growing desire to limit births in sub-Saharan Africa: meeting the challenge. Global Health: Science and Practice 1(1), 97-107.

Vollset SE, Goren E, Yuan CW, Cao J, Smith AE, Hsiao T and Murray CJ (2020) Fertility, mortality, migration, and population scenarios for 195 countries and territories from 2017 to 2100: a forecasting analysis for the Global Burden of Disease Study. The Lancet 396(10258), 1285-1306

Von Elm E, Altman DG, Egger M, Pocock SJ, Gøtzsche PC and Vandenbroucke JP (2007) The Strengthening the Reporting of Observational Studies in Epidemiology (STROBE) statement: guidelines for reporting observational studies. Annals of Internal Medicine 147(8), 573-577.

Westoff CF (2012) Unmet need for modern contraceptive methods. DHS Analytical Studies No. 28. ICF Macro, Calverton, MD. URL: http://measuredhs.com/pubs/pdf/AS28/AS28.pdf (accessed 24th May 2021).

Westoff CF and Koffman D (2010) Birth spacing and limiting connections. DHS Analytical Studies No. 21. ICF Macro, Calverton, MD. URL: http://www.measuredhs.com/pubs/pdf/AS21/AS21.pdf (accessed 24th May 2021).

Yaya S, Uthman OA, Ekholuenetale M and Bishwajit G (2018) Women empowerment as an enabling factor of contraceptive use in sub-Saharan Africa: a multilevel analysis of cross-sectional surveys of 32 countries. Reproductive Health 15(1), 1-12

Cite this article: Adu C, Frimpong JB, Mohammed A, Tetteh JK, Budu E, Ahinkorah BO, and Seidu A-A (2023). Safer sex negotiation and parity among women in sub-Saharan Africa. Journal of Biosocial Science 55, 74-86. https://doi.org/10.1017/ S0021932021000651 